\title{
PELA GESTAÇÃO DE OUTRAS SAÚDES E INCONTÁVEIS MODOS DE SER/ESTAR O MUNDO
}

\author{
Catia Paranhos Martins (Psicologia/UFGD - \\ catiamartins@ufgd.edu.br)
}

\begin{abstract}
RESUMO
Este texto é um exercício de pensamento que toma aspectos da saúde materna e da saúde indígena/indigenista de Dourados e região como dispositivos para questionar o presente e o que nos acontece. O cenário é paradoxal e marcado por inúmeras disputas. A força da monocultura produz o empobrecimento da vida e assujeitamentos de várias ordens. Num enfraquecimento de diversas formas de existência, as experiências estão cada vez mais restritas aos guetos identitários e as políticas de saúde servem, comumente, como estratégia para reafirmar as perspectivas naturalizantes. Dentre os desafios, destaco: como ampliar o compromisso coletivo como a vida quando o presente é o Brasil pós-golpe?
\end{abstract}

PALAVRAS-CHAVE: Saúde, cartografia, psicologia social

\section{FOR THE GESTATION OF ANOTHER HEALTH AND INCONTABLE WAYS OF BEING THE WORLD}

\begin{abstract}
This text is an exercise in thinking that takes aspects of maternal health and the indigenous /indigenist health of Dourados and region as devices to question the present and what happens to us. The scenario is paradoxical and marked by numerous disputes. The power of monoculture produces the impoverishment of life and subjection of several orders. In a weakening of various forms of existence, experiences are increasingly confined to identity ghettos and health policies commonly serve as a strategy to reaffirm the naturalizing perspectives. Among the challenges, I highlight how to broaden the collective commitment as life when the present is Brazil post-coup?
\end{abstract}

KEY WORDS: Health, cartography, social psychology 
Este texto ${ }^{1}$ é um exercício de pensamento construído no fio da navalha entre o que sei e a pesquisadora que almejo ser. Por isso já inicio com uma advertência: as ideias apresentadas aqui estão em diferentes estágios de amadurecimento e trazem inquietações e estranhamentos sobre um cenário que é comum e não deveria ser. Ensaiar uma cartografia é uma "experiência modificadora de si no jogo da verdade (...) um exercício de si, no pensamento" (FOUCAULT, 1984:13).

A saúde, como produção de cuidado e dimensão da cidadania de qualquer uma/um e de todos nós, é uma preocupação de meus estudos atuais e anteriores (MARTINS, 2015). Continuo no que compreendo ser a tarefa de cartografar o que nos acontece, por enxergar os intoleráveis do presente. Destaco uma questão norteadora: como ampliar o compromisso com a vida coletiva?

A partir de minhas andanças pelo País como consultora do Ministério da Saúde, por estudar e trabalhar pelo Sistema Único de Saúde (SUS), conheci muitos Brasis. Cito, para ilustrar, o Sul e Sudeste maravilhas com concentração de hospitais, equipamentos para diagnóstico e médicos, em contraposição ao vazio assistencial na região Norte. O cotidiano de trabalho na Política HumanizaSUS e os encontros com os inúmeros profissionais de diferentes localidades deste país continental ensinaram-me que os desafios da saúde não são técnicos, mas sim políticos (LANCET, 2011).

Para problematizar os muitos Brasis, a saúde como política e os desafios que gostaria que fossem nossos, enfatizo a saúde materna e a saúde indígena/indigenista como dois dispositivos para construir essas considerações pela gestação de outras saúdes e incontáveis modos de ser/estar no mundo. Um dispositivo, para Foucault e Deleuze, é uma rede com função estratégica formada por inúmeras linhas de diferentes naturezas que configuram uma

\footnotetext{
${ }^{1}$ Fragmentos desta discussão foram apresentados e debatidos nos seguintes eventos da UFGD: I Colóquio in(ter)disciplinar Michel Foucault, na mesa "Devires-corpos (in)disciplinadxs e(m) Foucault", coordenada por Simone Becker e composta por Esmael Oliveira, Rodolfo Arruda Leite de Barros e por mim; e no IV Congresso Iberoamericano de Arqueologia, Etnologia e Etno-história "Antropologia Sociocultural e suas interfaces disciplinares", no Grupo de Trabalho "Devires-desejos dissidentes e $(\mathrm{m})$ direitos humanos", coordenado por Esmael Oliveira e Simone Becker, ambos em 2017.
} 
máquina de fazer ver e falar, as linhas de visibilidade e enunciação, articuladas com as dimensões de poder e criação, as linhas de força e de subjetivação (DELEUZE, 2005).

\section{SAÚDE MATERNA}

Alguns aspectos que compõem este País quando o recorte é a vida de mulheres/mães no parto e no nascimento: altos índices de mortalidade materno-infantil, mesmo comparado a outros países da América Latina; assistência à saúde que desconsidera as evidências científicas $^{2}$ (OMS, 1996); a mais alta taxa de cesáreas do mundo; e, 25\% das mulheres declaram ter sofrido violência no parto, nos hospitais públicos e privados (BRASIL, 2014).

Para diminuir a mortalidade materna e infantil é necessário enfrentar o "paradoxo perinatal" (DINIZ, 2009), ou seja, o fato de que a ampliação do acesso aos serviços e às tecnologias em saúde não corresponde a melhores resultados para mulheres e bebês. Segundo Diniz, “[...] nos últimos 20 anos, houve uma melhoria nos indicadores da saúde materna no Brasil, assim como grande ampliação do acesso aos serviços de saúde. Paradoxalmente, não há evidências de melhoria na mortalidade materna" (DINIZ, 2009: 313). Reverter o atual modelo assistencial tecnocrático e iatrogênico implica produzir mudanças de inúmeras ordens.

As transformações necessárias para mudança de modelo vão desde o lugar ocupado pela mulher/mãe e a sua rede social na gestação, parto e nascimento ainda de submissão ao saber biomédico/masculino; na compreensão do parto como evento fisiológico, cuja assistência deve centrar-se no protagonismo da mulher e nas boas práticas pautadas nas melhores evidências científicas (OMS, 1996); na alteração dos modos de organizar o trabalho em saúde, que ainda se configura tal como uma linha de montagem; na promoção de diálogos entre os diversos pontos da atenção e da gestão para a tessitura de uma rede de cuidados

\footnotetext{
${ }^{2}$ Na condução do parto normal, a OMS (1996) caracteriza como boas práticas (pautadas na fisiologia e no protagonismo da mulher) em oposição às nocivas (enema, restrição de dieta, posição supina, episiotomia de rotina, ausência de métodos farmacológicos e/ou não para o alívio da dor, sucessivos exames de toque vaginal, dentre outros) ou sem comprovação científica da eficácia. Para detalhamento, sugiro "O modelo obstétrico e neonatal que defendemos e com o qual trabalhamos", de Andrade e Lima, no Caderno HumanizaSUS (BRASIL, 2014).
} 
intersetorial; na ampliação dos direitos sexuais e reprodutivos, com destaque para a legalização do aborto (ESTADÃO, 2016); no enfrentamento radical das desigualdades sociais, do machismo, do racismo, das iniquidades em saúde e das violências obstétricas, que fazem profissionais e serviços cometerem iatrogenias e atrocidades em nome do (suposto) cuidado; dentre outros aspectos. (BRASIL $\left.{ }^{3}, 2014\right)$

Os desafios elencados acima se colocam também para Dourados-MS e foram debatidos no "I Seminário de prevenção de agravos à saúde materno-infantil e III Encontro temático do Projeto Educação e Trabalho: PET GraduaSUS", organizado em parceria pela Secretaria Municipal de Saúde (SEMS Dourados), Universidade Estadual de Mato Grosso do Sul (UEMS) e Universidade Federal da Grande Dourados (UFGD), em 25/07/2017. Das importantes discussões realizadas pelos trabalhadores do SUS e pesquisadores presentes, destaco os 10 óbitos hospitalares em 2015, sendo 4 mulheres indígenas, 5 pardas e 1 branca.

As principais causas de morte de mulheres relacionadas ao período da gestação, parto e nascimento no País são as hemorragias pós-parto, pressão alta, infecções e complicações relacionadas ao aborto inseguro. $\mathrm{O}$ que as mortes acima evidenciam? Repito a pergunta do início do texto: como ampliar o compromisso coletivo com a vida de qualquer uma?

As contribuições de Foucault $(2008 ; 2007 ; 2006)$ sobre a história da medicina, do hospital, o nascimento da clínica e das políticas de saúde, bem como a configuração desses como estratégias biopolíticas, são fundamentais para a compreensão das sujeições dos corpos das mulheres nos últimos séculos. O cenário é composto pelo projeto da sociedade capitalista e da consolidação do Estado Moderno.

É no final do século XVIII que a medicina inaugura uma nova maneira de olhar e falar sobre o que se torna visível, o corpo anatomopatológico. A questão deixa de ser "o que é que você tem?", para buscar a exata localização da doença com “onde lhe dói?" (FOUCAULT, 2006). Ao longo do século XIX ocorre o processo de consolidação da profissão médica e o monopólio legal deste saber sobre a saúde. Em conformidade ao projeto social, a medicina contribuiu para o saneamento dos espaços públicos, ordenação da vida familiar, manutenção

\footnotetext{
${ }^{3}$ Os apontamentos acima ainda caracterizam o triste cenário nacional, entretanto há incontáveis experiências que compõem um "SUS que dá certo" e que não serão abordadas aqui. A Rede Cegonha, em curso, é uma estratégia nacional que fomenta a humanização do parto e do nascimento para diminuição da mortalidade materna e infantil, sendo construída entre os entes federativos, movimentos sociais e academia.
} 


\section{Nanduty}

ISSN:2317-8590

da força de trabalho e aprimoramento da população e da raça na produção de indivíduos adequados, dentre outros aspectos da vida disciplinada e normatizada.

A medicalização da sociedade ocidental é debatida por Foucault e Illich (1975), dentre tantos outros. Saliento as ressonâncias de ambos no trabalho de Vieira (2002), que problematiza a 'natureza' e a medicalização do corpo feminino. Para a autora, as normas tiveram a tarefa fundamental de regulação e controle do que foi configurado como a "essência" do corpo feminino. Os eventos fisiológicos foram transformados em doenças, uma poderosa fonte sexista. Assim, gravidez, parto, amamentação, loucura menstrual, menopausa e o amor entre mulheres são acontecimentos a serem tratados pelos saberes médicos e psicológicos.

Vieira (2002) debruça-se sobre as "Theses Inaugurais", obrigatórias para a obtenção do título de médico, apresentadas às faculdades da Bahia e do Rio de Janeiro no final do século XIX e início do XX. Como em um garimpo, a autora encontra nas theses o que considero como pérolas para essa problematização, tais como: a dúvida se haveria desenvolvimento cerebral nas mulheres; as medidas cerebrais menores justificadas pela energia corporal centrada no desenvolvimento do aparelho reprodutor; e a capacidade maternal excluía as qualidades não maternais. E dos preciosos exemplos, ressalto Marie Renotte, médica francesa que atuou no Brasil, que já em 1895 criticava o sexismo no saber sobre a mulher: "correr não convém, gritar é proibido, enfim escrava de suas emoções mais inocentes, a mulher até no seu rir é sujeita às regras".

Atualmente, as principais causas de morte de mulheres são: câncer, doenças cardiovasculares e causas externas, evidenciando o feminicídio ainda subnotificado (FLEURY- TEIXEIRA, 2015). Mas a vida das mulheres é medicalizada para a concepção, parto e contracepção. O modelo médico foi construído em resposta à falta de alternativas para a solução de questões sociais. O controle populacional emerge como problema cujas respostas são médico-cirúrgicas. Usa-se a tecnologia, característica da Modernidade, como solução em detrimento da Educação, que poderia privilegiar a cidadania e os direitos humanos. Assim, a genealogia das sujeições do corpo feminino, produzida por Vieira (2002), serve aqui para 
denunciar o lugar destinado às mulheres e questionar as colagens excessivas que reiteram a regulação de corpos e experiências sempre ou em vias de adoecimentos.

Embora ciente de que há questionamentos em aberto e aspectos a serem discutidos, trarei mais ingredientes para este exercício de pensamento. A seguir, breves considerações sobre a saúde indígena/indigenista ${ }^{4}$.

\section{SAÚDE INDÍGENA/INDIGENISTA}

O segundo dispositivo é também um convite/provocação para pensar o que nos acontece, para caracterizar o que é comum e não deveria ser; a violação de direitos dos povos indígenas de Dourados e região. Aqui estão mais de 13 mil pessoas que se declaram das etnias Kaiowá, Guarani ou Terena. Essas fazem parte do cotidiano da cidade, sendo impossível não enxergar as frequentes violações de direitos e o genocídio que marcam os últimos séculos.

As disputas pela terra e o aumento das taxas de homicídios, de crianças de baixo peso, de indígenas cumprindo pena no sistema carcerário, de suicídio, de assassinatos de lideranças indígenas, dentre outros aspectos, são constantes nas publicações e na mídia (BOM MEIHY, 1991; PEREIRA, 2015; CIMI, 2011, 2013). O Estado de Mato Grosso do Sul ocupa o desonroso $1^{\circ}$ lugar em assassinatos de indígenas no País (CIMI, 2013), aspecto já naturalizado seja pela conivência coletiva, seja pela omissão do poder público.

Das inúmeras entradas possíveis para problematizar a saúde, destaco a expectativa de vida. No Mato Grosso do Sul, segundo o IBGE, é de 75 anos. Já na população indígena do Distrito Sanitário Especial Indígena MS é de 34,7 anos (FERNANDES, 2016). Embora o indicador promova uma generalização e deixa escapar aspectos fundamentais para compreensão da vida desses coletivos, aqui serve para ressaltar que morar no centro ou na periferia de Dourados, ser douradense e indígena marca a vida, até quando e onde se pode ir.

\footnotetext{
${ }^{4}$ Destaco que há duas categorias "saúde indígena" e "saúde indigenista" cujas fronteiras são borradas no cotidiano da vida. Por apostar na micropolítica e nas políticas públicas voltadas à saúde indígena pautadas na participação dos indígenas em sua gest(aç)ão, a ênfase será ao longo do artigo no uso da categoria "saúde indígena".
} 
Continuo com a questão norteadora sobre como ampliar o compromisso coletivo com a vida. Neste território, parece-me que a monocultura empobrece não somente o solo, mas há a produção de um deserto para as invenções e as expressões dos diferentes modos de ser/estar no mundo. Uma das muitas questões ainda sem resposta: até quando? (BECKER; OLIVEIRA; MARTINS, 2016).

Exercitar o pensamento é desnaturalizar a morte de mulheres/mães, aqui em especial as não-brancas, bem como a diferença significativa entre se declarar kaiowá e/ou douradense. Interesso-me por enxergar o cenário de barbárie, tomá-lo como intolerável no presente e almejo, de forma concomitante, conhecer as riquezas dos saberes e práticas tradicionais relacionados com a saúde como potência de resistência aos inúmeros modos de aprisionamento da vida. Kaiowá e Guarani ${ }^{5}$ lutam contra o etnocentrismo, contra a escravidão de ontem e de hoje, pelo direito à terra e por uma vida digna; dignidade esta que só pode ser produzida a partir de sua cosmologia, dimensão em que estou empenhada em aprender e que, por enquanto, teço somente breves comentários.

Caminho tateando como algumas comunidades Kaiowá e Guarani de Dourados e região produzem saúde. No cotidiano de trabalho, principalmente na Residência Multiprofissional de Saúde Indígena do Hospital Universitário da Grande Dourados, dentre outros espaços que habitar a periferia me proporciona, aprendo que saúde é luta, que terra não é sujeira, que a vida tem mais dimensões do que eu supunha. Aprendo sobre dimensões até então incompreensíveis aos meus olhos formatados pela racionalidade hegemônica, composta pela história universal e pela perspectiva etnocêntrica. Novos campos de possíveis se abrem a partir da perspectiva do tempo kaiowá, da importância da luta pelo tekoha para se ter saúde, da parentela e o fogo doméstico como dimensões da política, e da missão que o povo Kaiowá tem em pacificar as pessoas não-indígenas.

Se as dúvidas são inúmeras, já posso afirmar que é necessário desaprender oito horas por dia na construção de outros modos de cuidar em Saúde Indígena. A Saúde que almejo estudar, ensinar e produzir é uma construção coletiva, implica num modo singular de fazer saúde com as pessoas e não para elas. Destaco, ainda, o abismo entre o funcionamento do

\footnotetext{
${ }^{5}$ Justifico a ausência do povo Terena em minhas considerações já que tenho poucos espaços de encontro e diálogo com elas e eles.
} 
Estado e das políticas de saúde e como se produz o bem viver, teko porã, e a importância da mobilidade, as andanças inerentes à vida e as riquezas do caminhar, o oguatá pyahu, que marcam esses povos (BENITES, 2014; RODRIGUES, 2016).

\section{CONSIDERAÇÕES FINAIS: COMO SONHAR QUANDO O PRESENTE É O BRASIL PÓS-GOLPE?}

Mulheres e indígenas servem aqui como dispositivos para pensar as hierarquias que constituem o presente. E, aos inúmeros desafios para a vida coletiva - que já foram apontados acima -, acrescento mais uma dimensão problemática. Os vieses que distinguem pobres/ricos, não-brancos/brancos, mulheres/homens, homossexuais/héteros, periferia/centro, dentre outras polaridades significativas, que interferem nos modos de tocar a vida e condenam uma parcela da população ao acesso precário, à desassistência em saúde e até à morte. Entretanto, as polaridades são "máquinas binárias" (DELEUZE; PARNET, 1996) e deixam escapar dimensões tão importantes quanto as já destacadas.

Existe outro tipo de pobreza/doença que também me interessa, mas que não pode ser medida. Há algo que produz um empobrecimento da vida, é a "gorda saúde dominante", para Deleuze (1997). Numa tentativa de enfraquecimento de diversas formas de existência, as experiências humanas estão cada vez mais restritas aos guetos identitários e às políticas de saúde, comumente servem como estratégia para reafirmar as perspectivas naturalizantes.

Limito-me a problematizar a forma mulher-padrão. A mulher, objeto generalizado e naturalizado da política de saúde, é ou será mãe, está limitada à sua constituição biológica, racional, branca, cristã, heterossexual, escolarizada e moradora da cidade. Essa forma padrão não corresponde à experiência concreta das mulheres em sua pluralidade, deixando de fora as que se reconhecem como indígenas, negras, ciganas, lésbicas, ribeirinhas, as que não podem ou não almejam a maternidade, as que vivem em situação de rua, campo ou floresta, as que beiram ou estão inundadas pela insanidade, as que se produzem como mulher a despeito do sexo biológico, dentre tantas outras formas de ser/estar. 
Enfrentar o apequenamento da existência, que se concretiza desde os modos de subjetivação até as políticas de saúde, bem como inúmeras outras combinações de sutilezas e deliberações que nos mantêm condenados a um padrão de vida triste, implica na produção de um olhar para as muitas formas de ser/estar e suas singulares compreensões de saúde, corpo e cuidado e, ainda, na "[...] desconstrução da sinonímia gênero-mulher e mulher-mãe" (MEYER, 2003). Implica reafirmar o compromisso ético - tarefa coletiva e inconclusa - na construção de políticas e práticas em saúde que promovam modos de vida em que graus maiores de autonomia serão almejados. Mas como pensar e sonhar quando o presente é o Brasil pós-golpe?

"Não é fácil morar da faixa de Gaza", ao som de Ruspô (2016) permito-me afirmar que não é fácil construir uma Saúde que precisa caminhar de mãos dadas com a democracia, lema do movimento sanitário desde 1970, como valor a ser compartilhado com todos nós e qualquer uma/um. Este é o fatídico ano de 2018. Tal como na risível campanha de Michel Temer, "O Brasil voltou, 2 anos em 20”, e os retrocessos são inúmeros em um curto período de tempo. O País vive um golpe atrás do outro desde o impeachment, sem a comprovação de crime, de Dilma Rousseff, a primeira mulher eleita no País para a Presidência da República. Os desdobramentos seguintes envolvendo Congresso Nacional, Judiciário, Mercado e grande Mídia apontam para a fragilidade dos valores democráticos.

É preciso defender o SUS, inclusive, do Ministro da Saúde, cuja campanha para deputado foi financiada por um importante grupo da saúde suplementar, que se posiciona contrário aos princípios constitucionais. "Temos que diminuir o tamanho do SUS", é o que disse o Ministro ao assumir a pasta (UOL, 2018). Muitas mortes, incluindo de mãe e crianças, de indígenas ou não, poderiam ser evitadas, caso tivéssemos um movimento da radicalização da saúde como direito. Como já dito, os desafios são políticos e não técnicos. Como reinventar a política ou até outras políticas?

Não é fácil morar em Dourados, tampouco é fácil morar no Brasil. Aqui a Comissão Parlamentar de Inquérito que investigava a Fundação Nacional do Índio e Instituto Nacional de Colonização e Reforma Agrária, a CPI FUNAI - INCRA 2, foi comandada pela bancada ruralista e o Relatório Final pede a condenação de antropólogos, juristas e entidades que 
lutam pela dignidade dos povos indígenas, já que estes estão 'inventando' terras indígenas, trazendo índios do Paraguai e declarando-os brasileiros (RACISMO AMBIENTAL, 2017). Além disso, merece destaque que desde a Constituição de 1988 os avanços no respeito aos povos tradicionais e na demarcação de terras são incipientes. Como aprendi com uma liderança, "ontem matavam à bala, hoje usam a caneta". Embora não haja compromisso com a vida coletiva por parte de setores importantes neste País, Kaiowá e Guarani resistem há mais de 500 anos.

Dos inúmeros golpes, destaco a Emenda Constitucional n ${ }^{\circ} 95$ que congelou por 20 anos os gastos públicos, incluindo a Saúde e Educação. Houve, ainda, a retirada de mais recursos financeiros das políticas sociais para reduzir o preço do diesel no País, após a recente greve dos caminhoneiros. Este combustível é altamente poluente e já tem data de proibição em vários países da Europa. Aqui o compromisso é com o mercado, e os cortes de recursos no SUS incluem tanto a Saúde Indígena e a demarcação de terras, quanto às políticas de igualdade e enfrentamento da violência contra as mulheres, dentre outras (ABRASCO, 2018).

Em 2013, ainda na gestão de Dilma, o País parou em decorrência da greve dos caminhoneiros. Adesivos com uma caricatura da Presidenta, de pernas abertas, foram colados nos tanques dos carros. A bomba de combustível entrava na vagina da mulher caricaturada. Novamente, em 2018, caminhoneiros trancaram importantes estradas do país e houve, inclusive, crise de abastecimento em várias cidades. Não houve caricaturas fazendo menção à violência sexual mesmo quando o Presidente tem a menor popularidade da história. Concordo com as leituras que apontam a misoginia como uma marca do Golpe em curso. "Bela, recatada e do lar", slogan de uma revista semanal cuja pretensão era exaltar as 'qualidades' da então Primeira Dama, serve como síntese do lugar - ainda - destinado às mulheres de submissão cuja 'essência' é a procriação.

Acrescento, para caracterizar o cenário de retrocessos, as iniciativas "Escola sem Partido", "Ideologia de Gênero", "Estatuto da Família", "Estatuto do Nascituro" e "Cura gay", que embora merecessem análises mais cuidadosas sobre objetivos, métodos, ilegalidades, imoralidades e consequências nefastas na vida de todos nós, de qualquer uma/um, aqui servem como exemplos que reiteram a norma cristã, patriarcal e neoliberal. São essas 


\section{Nanduty}

ISSN:2317-8590

supostas iniciativas em defesa da vida e da família, propagadas por representantes políticopartidários, religiosos e pessoas que se autodeclaram 'cidadãos de bem'. Entretanto, as mesmas iniciativas não incluem a luta radical pela vida de qualquer uma/um, de pessoas indígenas, negras, camponesas, gays, lésbicas, transexuais, putas, sem terra, sem teto, loucas, drogaditas, presidiárias e pobres, assim como os arranjos familiares não-heterossexuais, tampouco a parentela kaiowá, dentre tantas outras formas de organização da vida. As existências que diferem da forma padrão - macho sul-mato-grossense do agronegócio - são as vidas infames, abjetas e descartáveis.

Portanto, "[...] qual saúde bastaria para libertar a vida em toda parte onde esteja aprisionada pelo homem e no homem, pelos organismos e gêneros e no interior deles?" (DELEUZE, 1997: 14).

Estar no fio da navalha, entre o que sei e as questões que coloco para provocar o pensamento, é a tentativa de inventar novos problemas ao tomar mulheres e indígenas como devires, como vidas que questionam os guetos identitários, a norma e os intoleráveis do presente. É com Deleuze e Guattari (1992, p. 68) que justifico minha cartografia: "[...] se o pensamento procura, é menos à maneira de [alguém] que disporia de um método, que à maneira de um cão que pula desordenadamente...". E com essas provisórias considerações exercito um pensamento que possa gestar - quiçá por alguns segundos - desejos, corpos e vidas que não se querem disciplinados, silenciados, assujeitados, binarizados e tampouco coniventes com o atual estado de coisas. Escrever é tentar mapear um jogo de forças, é saber que as forças fogem para todos os lados ao mesmo tempo, é habitar um paradoxo, “[...] escrever é lutar, resistir; escrever é vir-a-ser; escrever é cartografar" (DELEUZE, 2005: 53).

\section{REFERÊNCIAS}

ABRASCO. Associação Brasileira de Saúde Coletiva. 2018. Nota contra os cortes na saúde para subsidiar o diesel. In: https://www.abrasco.org.br/site/outras-noticias/notasoficiais-abrasco/nota-abrasco-contra-os-cortes-na-saude-para-subsidiar-o-diesel/34448/ (acesso em 2 de junho de 2018). 
BECKER, Simone, OLIVEIRA, Esmael; MARTINS, Catia Paranhos. 2016. "Onde fala a bala, cala a fala": resistências às políticas da bancada da Bala, do Boi e da Bíblia em Mato Grosso do Sul. Dourados. In: http://www.redehumanizasus.net/94812-onde-falaa-bala-cala-a-fala (acesso em 19 março 2018).

BOM MEIHY, José Carlos Sebe. 1991. Canto de Morte Kaiowá. São Paulo, Loyola.

BRASIL. Ministério da Saúde. 2014. Caderno HumanizaSUS Parto e do Nascimento. Universidade Estadual do Ceará. Brasília, Ministério da Saúde.

BENITES, Eliel. 2014. Oguata Pyahu (Uma Nova Caminhada) no Processo de Desconstrução e Construção da Educação Escolar Indígena da Aldeia Te'ýikue. Dissertação de Mestrado em Educação, Universidade Católica Dom Bosco.

CIMI. Conselho Indigenista Missionário. 2015. Um olhar sobre a saúde dos povos indígenas. In: https://cimi.org.br/pub/Porantim/2015/Encarte_Porantim379_out2015.pdf (acesso em 20 de junho de 2018).

. Relatório Violência contra os povos indígenas no Brasil - dados de 2013. Brasília DF: CIMI, 2013.

DELEUZE, Gilles. 2005. Foucault. São Paulo, Brasiliense.

. 2000. Conversações. Rio de Janeiro, Editora 34.

1997. Crítica e Clínica. São Paulo, Editora 34.

; PARNET, Claire. 1996. Diálogos. São Paulo, Escuta.

; GUATTARI, Félix. 1992. O que é a filosofia? São Paulo, Editora 34.

DINIZ, Simone Grilo. 2009. "Gênero, saúde materna e o paradoxo perinatal". Revista Brasileira de Crescimento e Desenvolvimento Humano, São Paulo, 19 (2): 313-326.

ESTADÃO. 2016. Disponível em: http://saude.estadao.com.br/noticias/geral,diariamente-4mulheres-morrem-nos-hospitais-por-complicacoes-do-aborto, 1000009528 (acesso em 20 junho 2018).

FERNANDES Tanise Oliveira. 2016. A Saúde nas Aldeias Indígenas de Abrangência do Polo Base de Dourados. Trabalho de Conclusão de Curso de Especialização em Saúde Pública, Faculdade de Saúde Pública.

FLEURY-TEIXEIRA, Elizabeth (Org.). 2015. Dicionário Feminino da Infâmia: acolhimento e diagnóstico de mulheres em situação de violência. Rio de Janeiro, FIOCRUZ. 
FOUCAULT, Michel. 2008. Nascimento da biopolítica: Curso dado no Collège de France (1978-1979). São Paulo, Martins Fontes.

2007. Microfísica do Poder. Rio de Janeiro, Graal.

2006. Nascimento da Clínica. Rio de Janeiro, Universitária.

. 1984. História da Sexualidade 2: o uso dos prazeres. Rio de Janeiro, Graal.

ILLICH, Ivan. 1975. A expropriação da saúde. Nêmesis da Medicina. Rio de Janeiro, Nova Fronteira.

LANCET. 2011. "Saúde no Brasil". The Lancet. In: http://www.abc.org.br/IMG/pdf/doc574.pdf (acesso em 5 de maio de 2016).

MARTINS, Catia Paranhos. 2015. A Política Nacional de Humanização na produção de inflexões no modelo hegemônico de cuidar e gerir no SUS: habitar um paradoxo. Doutorado em Psicologia, Universidade Estadual Paulista.

MEYER, Dagmar. 2003. "Educação, Saúde e modos de inscrever uma forma de maternidade nos corpos femininos". Revista Movimento, Porto Alegre, 9 (3): 33-58.

ORGANIZAÇÃO MUNDIAL DE SAÚDE. 1996. Assistência ao parto normal: um guia prático. Genebra, OMS.

PEREIRA, Levi Marques. 2014. A atuação do órgão indigenista oficial brasileiro e a produção do cenário multiétnico da Reserva Indígena de Dourados, MS. In: https://www.anpocs.com/index.php/papers-38-encontro/gt-1/gt21-1/8809-a-atuacao-doorgao-indigenista-oficial-brasileiro-e-a-producao-do-cenario-multietnico-da-reservaindigena-de-dourados-ms/file (acesso em 05 de maio de 2017).

. 2015. "A Reserva Indígena de Dourados: a atuação do Estado brasileiro e o surgimento de figurações indígenas multiétnicas". In: CHAMORRO, G.; COMBÈS, I. (org.). Povos Indígenas em Mato Grosso do Sul: histórias, cultura e transformações sociais. Dourados/MS: Ed. UFGD.

RACISMO AMBIENTAL. 2017.2 Disponível em: http://racismoambiental.net.br/2017/05/03/cpi-funai-incra-pede-a-condenacao-defalsos-indios-antropologos-entidades-e-procuradores-da-republica/ (acesso em 15 maio de 2018).

RODRIGUES, Paula Ap. Santos. 2016. Oguata Pyahu e a Residência Multiprofissional em Saúde Indígena: Um Novo Caminhar no Desafio de SUStentar. Trabalho de Conclusão 


\section{Nanduty}

ISSN:2317-8590

de Curso da Residência Multiprofissional em Saúde - Ênfase em Saúde Indígena, Universidade Federal da Grande Dourados.

UOL. 2016. Disponível em: http://www1.folha.uol.com.br/cotidiano/2016/05/1771901tamanho-do-sus-precisa-ser-revisto-diz-novo-ministro-da-saude.shtml (acesso em 17 maio 2016).

VIEIRA, Elisabeth Meloni. 2002. A medicalização do corpo feminino. Rio de Janeiro, FIOCRUZ. 